$12-2019$

\title{
Thin-Walled Steel Tubular Circular Columns with Uniform and Graded Thickness under Bidirectional Cyclic Loading
}

Qusay Al-Kaseasbeh

Iraj H.P. Mamaghani

University of North Dakota, iraj.mamaghani@UND.edu

How does access to this work benefit you? Let us know!

Follow this and additional works at: https://commons.und.edu/cie-fac

Part of the Civil Engineering Commons

\section{Recommended Citation}

Qusay Al-Kaseasbeh and Iraj H.P. Mamaghani. "Thin-Walled Steel Tubular Circular Columns with Uniform and Graded Thickness under Bidirectional Cyclic Loading" (2019). Civil Engineering Faculty Publications. 2.

https://commons.und.edu/cie-fac/2

This Article is brought to you for free and open access by the Department of Civil Engineering at UND Scholarly Commons. It has been accepted for inclusion in Civil Engineering Faculty Publications by an authorized administrator of UND Scholarly Commons. For more information, please contact und.commons@library.und.edu. 
Thin-Walled Steel Tubular Circular Columns with Uniform and Graded Thickness under Bidirectional Cyclic Loading

Qusay Al-Kaseasbeh ${ }^{1,2^{*}}$, Iraj H.P. Mamaghani ${ }^{2}$

${ }^{1}$ Dept. of Civil and Environmental Engineering, Mutah University, Mutah, Al-Karak, 61710, Jordan

${ }^{2}$ Dept. of Civil Engineering, Univ. of North Dakota, Grand Forks, ND, 58202, USA 


\begin{abstract}
Thin-walled steel tubular circular columns are becoming an increasingly attractive choice as cantilever bridge piers due to their architectural, structural and constructional advantages. This paper aims to evaluate the strength and ductility of thin-walled steel tubular circular columns with uniform thickness (BC) and graded thickness (BGC) under bidirectional cyclic lateral loading in the presence of constant axial force. The analysis is carried out using a finite-element model (FEM) which is substantiated based on the experimental results in the literature. Then, the proposed BGC column with size and volume of material equivalent to the BC column is investigated. As a part of this research, a comprehensive parametric study is carried out to investigate the effects of main design parameters including: radius-to-thickness ratio parameter (Rt), column slenderness ratio parameter $(\lambda)$, magnitude of axial load (P/Py), and number of loading cycles $(\mathrm{N})$ on the strength and ductility of both BC and BGC columns under bidirectional cyclic lateral loading. Finally, design formulae of ultimate strength and ductility of BC and BGC columns are derived.
\end{abstract}

Keywords: Thin-walled, Circular graded-thickness, Buckling, Ductility, Strength, Bidirectional cyclic loading 


\section{Introduction}

In regions with severe seismic activities, the integrity of civil engineering structures is exposed to an increased earthquake risk [1-3]. In response to these risks, thin-walled steel tubular columns are becoming an attractive choice for engineers/architects when designing modern buildings, elevated storage tanks, transmission towers, wind turbines, and onshore and offshore structures [4-7]. In addition, these columns are commonly used for elevated highway bridge piers [8] in regions with severe earthquakes due to their structural efficiency, attractive aesthetic appearance, high earthquake resistance, and potential for concrete infilling $[9,10]$. However, thin-walled steel columns are vulnerable to damage when subjected to severe earthquakes (e.g., the Kobe earthquake (1995), the Sichuan earthquake (2008), and the East Japan earthquake (2011)) [5,7,11-14]. Local buckling causes overall strength loss, ductility reduction, and even full collapse of these columns under constant axial force and unidirectional cyclic lateral loading $[15,16]$. The strength and ductility of circular thin-walled steel tubular columns depend on their radius-to-thickness ratio parameter $(\mathrm{Rt})$ and slenderness ratio parameter ( $\lambda$ ). Moreover, decreasing Rt and $\lambda$ improve the strength and ductility of these columns $[15,17,18]$. In reality, the earthquake ground motion is complex and 3D loading components acting simultaneously, as opposed to assumed unidirectional loading pattern [19-22]. Moreover, hysteretic behavior of thin-walled steel tubular columns under multidirectional cyclic lateral loading is expected to be more critical and severe than the same amplitude of unidirectional cyclic lateral loading. Since then, the hysteretic behavior of thin-walled steel tubular columns under bidirectional cyclic lateral loading was investigated by a number of researchers [20,2325]. The studies revealed that thin-walled steel tubular columns under bidirectional cyclic lateral loading experience an extensive degradation in strength and ductility compared to unidirectional cyclic lateral loading, and should be incorporated in the seismic design practice [20,24,26-29]. 
Thin-walled steel bridge piers are key structural components in bridge seismic design and acceptable to be modeled as a cantilever column [30]. Along with Rt and $\lambda$; cross-sectional configuration, cyclic lateral loading, and different parameters must be considered in the practical seismic design of the thin-walled steel tubular columns [26]. Up to date research focuses on the investigation of the uniform circular thin-walled steel tubular columns under uni/multidirectional cyclic lateral loading. As revealed in the literature, local buckling usually occurs near the column's base [16, 31,32]. To address this limitation and ensure an adequate strength and ductile behavior of thin-walled steel columns, thin-walled steel tubular circular columns with graded thickness have been recently proposed and investigated by the authors to eliminate and delay the local buckling under constant axial force and unidirectional cyclic lateral loading [15]. The authors' study concluded that graded-thickness thin-walled steel tubular circular column offers obvious improvements on the strength and ductility under constant axial force and unidirectional cyclic lateral loading [15].

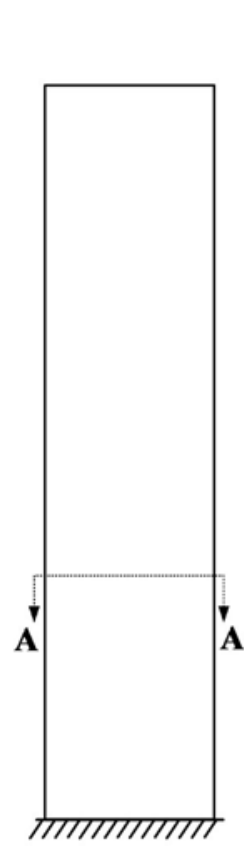

(a)



(b)

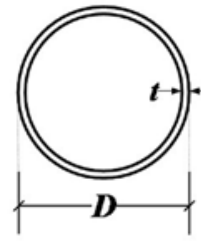

Section A-A

(c)

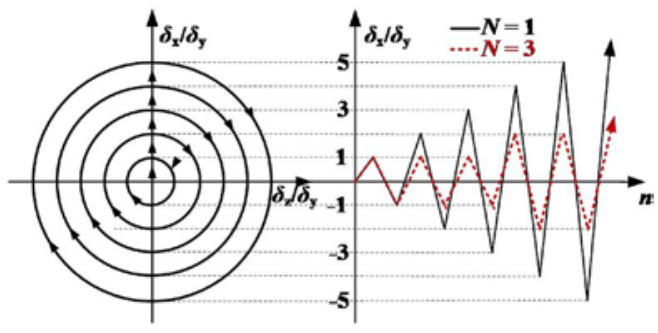

(d)

Fig. 1. Tested column model: (a) Column; (b) FE meshing; (c) Cross section; and (d) Loading program. 
This study aims to evaluate the strength and ductility of graded-thickness thin-walled steel tubular circular columns (denoted as BGC in the further text) under constant axial force and bidirectional cyclic lateral loading. To achieve this goal, a uniform thin-walled steel tubular circular column has been numerically analyzed under constant axial force and bidirectional cyclic lateral loading. The accuracy of the adopted FEM has been substantiated based on the experimental results in the literature [26]. Then, the proposed BGC column with size and volume of material equivalent to a uniform column (i.e., BC column) is investigated. The study results indicate that BGC columns show significant improvements in ultimate strength, ductility, and post-buckling compared to their counterpart BC columns, emphasizing the effect of the plate thickness and sectional configuration in the proposed BGC columns.

\section{Numerical model}

Finite element analysis is carried out using the finite-element software ABAQUS/Standard where material and geometric nonlinearities are considered [33]. The linear kinematic hardening model, von Mises yield surface, and associated plastic flow rule available in ABAQUS were adopted in the study. This model is used to simulate the inelastic behavior of materials that are subjected to cyclic loading [33]. More details about this model are reported in Refs. [34-37]. The accuracy of the employed FEM is validated with the experimental results (test PT3.5-1) available in the literature [26]. Rt and $\lambda$ are key design parameters in the practical design of thin-walled steel tubular circular columns, where Rt affects the local buckling and $\lambda$ controls the global buckling [15]. Rt and $\lambda$ of the column are defined as follows:

$$
R_{t}=\frac{D}{2 t} \frac{\sigma_{y}}{E} \sqrt{3\left(1-v^{2}\right)}
$$




$$
\lambda=\frac{2 h}{r} \frac{1}{\pi} \sqrt{\frac{\sigma_{y}}{E}}
$$

where $h=$ column height, $\mathrm{D}=$ column diameter, $t=$ plate thickness, $r$ = radius of gyration of cross section, $\sigma y=$ yield stress, $E=$ Young's modulus, and $v=$ Poisson's ratio. For the tested column (test PT3.5-1), $h=1460 \mathrm{~mm}, D=258.2 \mathrm{~mm}, t=3.5 \mathrm{~mm}, r=90 \mathrm{~mm}, \sigma y=350 \mathrm{MPa}, E=$ $206 \mathrm{GPa}$, and $v=0.3$ [26]. The analyzed cantilever column is assumed to be fixed at the base and subjected to constant axial force $(P)$ and bidirectional cyclic lateral displacement at the top, as shown in Fig. 1. The two-node beam element (B31) is employed for the upper part of the column, whereas the reduced integration four-node shell elements (S4R), which accurately consider the local buckling, are used for the lower part of the column.

All used elements are available in the ABAQUS/Standard library. The interface between S4R and B31 elements is modeled using MPC (multipoint constraint). For computational efficiency, the bottom portion of the lower part (equal to the cross-section diameter, $D$ ), where the local buckling usually occurs, is divided into 27 S4R elements. The remaining height of the lower part (2D) is divided only in 21 S4R elements. 40 S4R elements are used in the circumferential direction in the lower part of the column. The upper part of the column (height of $h-3 D$ ) is divided into B31 elements with size of $90 \mathrm{~mm}$. The above-stated mesh sizes are determined by trial and error and found to give more efficient and reasonable results. The initial geometrical imperfection and residual stresses are not considered in the current analysis as they were not quantified in the tested column [26]. A recent study by Chen et al. (2019) concluded that initial geometric and welding residual stresses have insignificant impact on the hysteretic behavior of thin-walled steel columns under cyclic lateral loading [38]. Moreover, it is confirmed 
by other researchers that initial geometrical imperfection and residual stresses reduce the initial stiffness and strength under monotonic loading but have insignificant effect under cyclic lateral loading following the first cycle [13,15,35,39-42]. Accordingly, the initial imperfection and residual stresses are not considered in this study.

\subsection{Cyclic loading protocol}

Among different bidirectional loading paths, the displacement-controlled circular cyclic lateral loading is adopted as the most critical and severe loading program, illustrated in Fig. 1d $[7,26]$. The adopted loading path is quasi-statically applied to the top of the column with constant axial force (P). In each loading step, the amplitude of the cyclic displacement is increased as a multiple of the yield displacement $(\delta y)$ which is defined by Eq. (3):

$$
\begin{aligned}
& \delta_{y}=\frac{H_{y} h^{3}}{3 E I} \\
& H_{y}=\left(\sigma_{y}-\frac{P}{A}\right) \frac{S}{h}
\end{aligned}
$$

where Hy, A, I, and S, respectively, are the lateral yield load (calculated in Eq. (4)), crosssectional area, moment of inertia, and elastic section modulus of the column, and other parameters are defined earlier [15,26].

\subsection{Comparison of numerical and experimental results}

The hysteretic behavior of the tested column, in both $\mathrm{X}$ and $\mathrm{Z}$ directions, obtained from the analysis is compared to the experimental results in the literature [26] and presented in Fig. 2. The solid line signifies the analysis results, while the experimental results are denoted with the dashed line. Hy and $\delta y$ are the lateral yield load and the yield displacement, respectively. In both 
$\mathrm{X}$ and $\mathrm{Z}$ directions, a relatively good agreement with the experimental results is noticed. The FEM predicts the ultimate strength of the column with 1.5\% error in X direction (FEM:

Hxmax/Hy $=1.33$, Experiment: Hxmax/Hy $=1.35$, see Figs. $2 a$ ) and $4 \%$ in $\mathrm{Z}$ direction (FEM:

Hzmax $/ \mathrm{Hy}=1.25$, Experiment: Hzmax/Hy=1.30, see Fig. $2 b)$. As the comparison results revealed, the FEM, using the kinematic hardening material model, is able to capture the structural behavior of thin-walled steel tubular circular columns with a reasonable accuracy considering the local buckling under constant axial force and bidirectional cyclic lateral loading. In Fig. 3, the buckling shape of the tested column [26] (see Fig. 3a) is compared to the FE buckling shape at the end of the analysis (see Fig. 3b). In both the experiment and FE analysis, the column bulged outward near the base and formed an elephant-foot-bulge buckling mode. As a result, the buckling shape is captured relatively well by the adopted FEM.
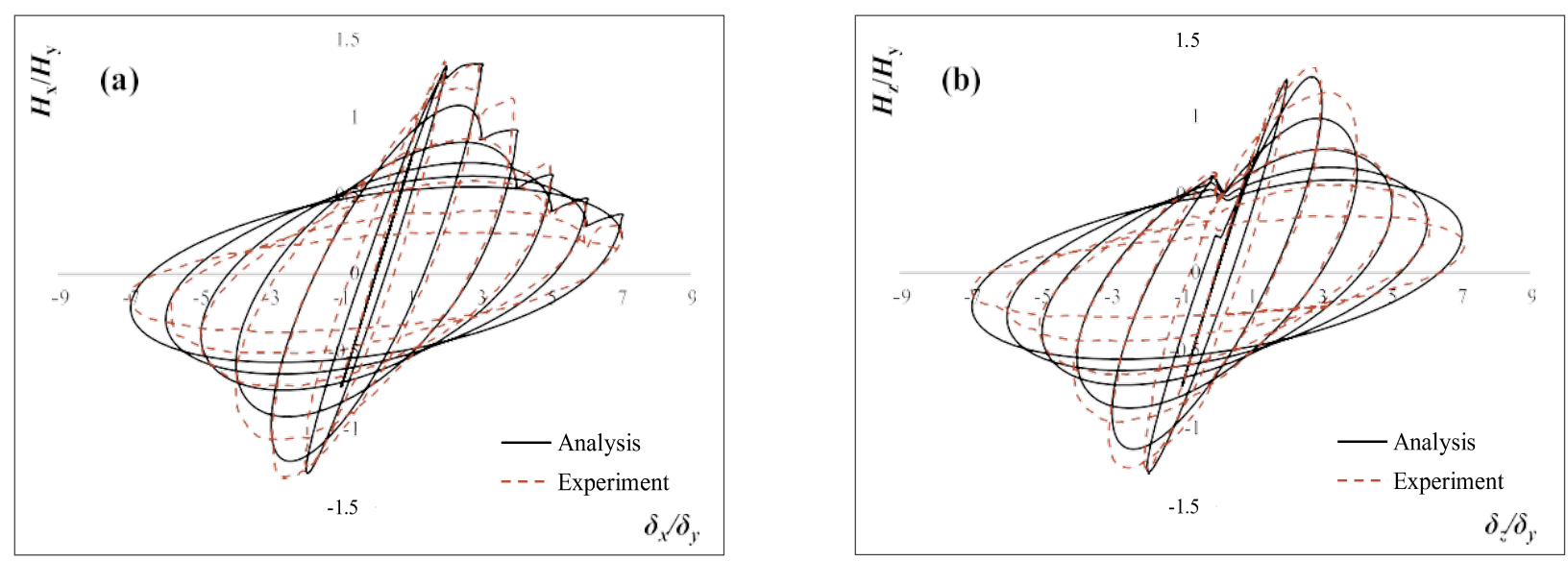

Fig. 2. Hysteretic curves of analysis and experiment of tested column. 


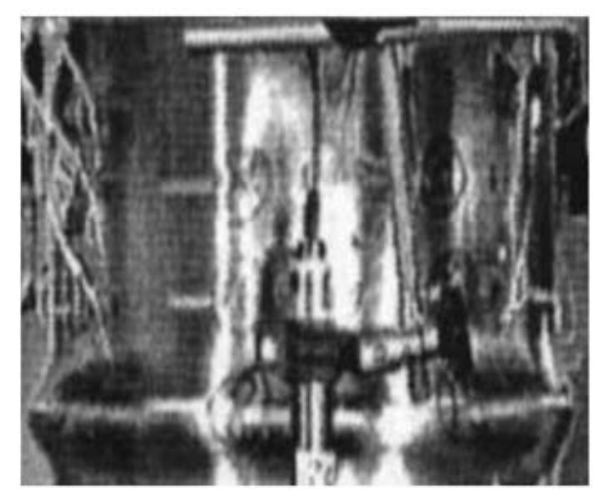

(a) Experiment [26]

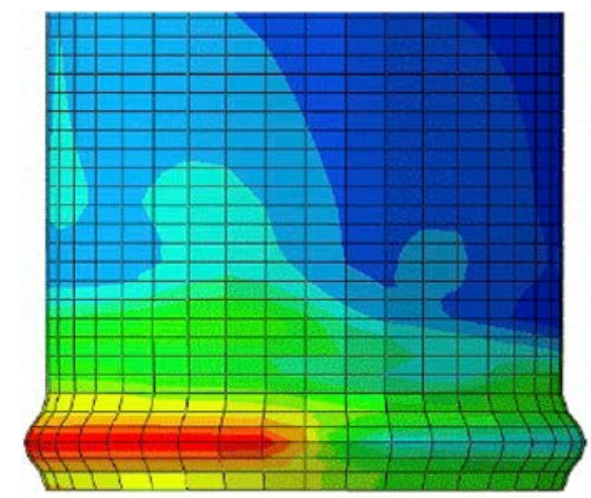

(b) FE Analysis

Fig. 3. Buckling of tested column

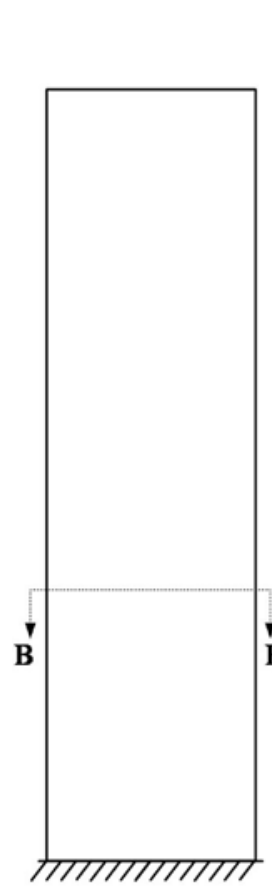

(a)

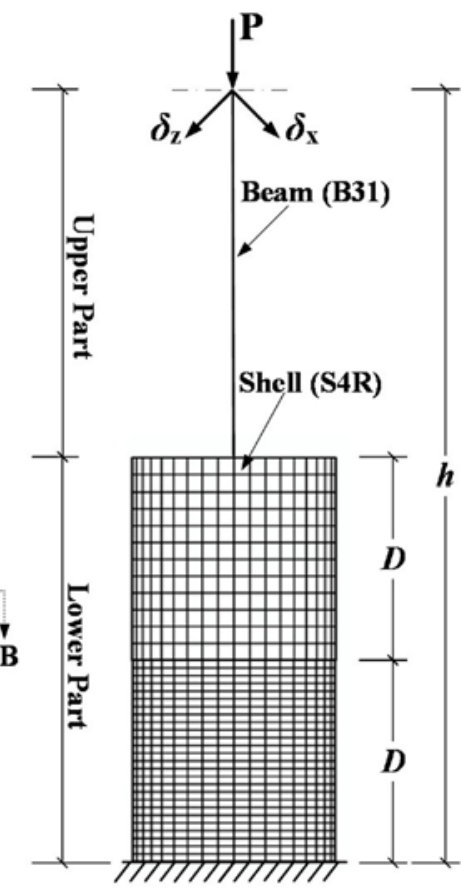

(b)

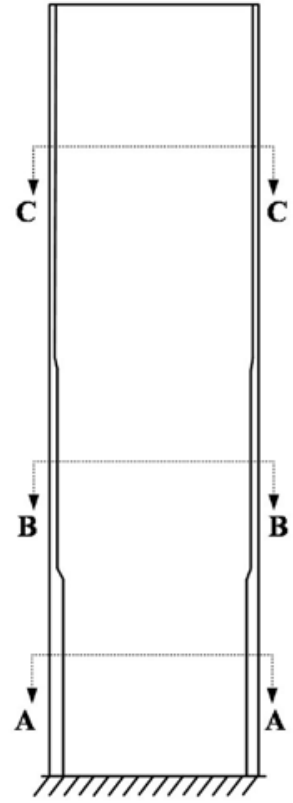

(c)

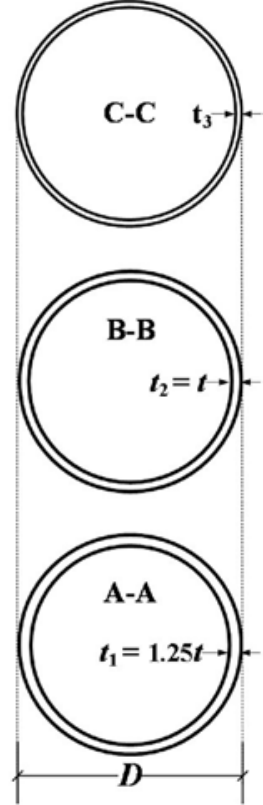

(d)

Fig. 4. (a) BC column, (b) FE meshing, (c) BGC column, and (b) Graded-thickness sections.

\section{Proposed thin-walled steel column with graded thickness}

Authors have recently proposed and investigated the overall behavior of the gradedthickness thin-walled steel tubular circular column to eliminate and delay the local buckling under constant axial force and unidirectional cyclic lateral loading [15]. The proposed BGC column has size and volume of material equivalent to BC column. The BGC column has three segments of constant cross sections along its height. The first and second segments have the 
same height, a height that is equal to the diameter of BC column. The third segment has a height of (h-2D) where h and D are kept the same for both BC and BGC columns as shown in Fig. 4b and c. In the proposed BGC column (see Fig. 4d), the first and second segments, respectively, have a thickness of 1.25t, and t where $\mathrm{t}$ is the thickness of the $\mathrm{BC}$ column. Finally, the thickness of the third segment, $\mathrm{t} 3$, is calculated by equating the volume of material in both $\mathrm{BC}$ and BGC columns. The above configuration of the BGC column was chosen based on which achieves favorable behavior by eliminating and/or mitigating local buckling near the base of the column. It should be mentioned that the purpose of the proposed column scheme is to eliminate or/and delay the local buckling near the base of the column. The material and geometrical properties of the BC and BGC columns are listed in Table 1. The same geometrical properties (except the plate thickness) are used for both types of BC and BGC columns, which are assumed to be made of the same carbon steel ASTM A36 [43].

Table 1: Geometrical and material properties of analyzed BC and BGC columns.

\begin{tabular}{|c|c|c|c|c|c|c|c|c|c|c|c|c|c|}
\hline \multicolumn{6}{|c|}{ BC Columns } & \multicolumn{8}{|c|}{ BGC Columns } \\
\hline \multirow[t]{2}{*}{ Column } & \multirow[t]{2}{*}{$\mathrm{h}(\mathrm{mm})$} & \multirow[t]{2}{*}{$\mathrm{t}(\mathrm{mm})$} & \multirow[t]{2}{*}{$\mathrm{R}_{\mathrm{t}}$} & \multirow[t]{2}{*}{$\lambda$} & \multirow[t]{2}{*}{$\mathrm{P} / \mathrm{Py}_{\mathrm{y}}$} & \multirow[t]{2}{*}{ Column } & \multirow[t]{2}{*}{$\mathrm{h}(\mathrm{mm})$} & \multicolumn{3}{|c|}{$\mathrm{t}(\mathrm{mm})$} & \multirow[t]{2}{*}{$\mathrm{R}_{\mathrm{t}}$} & \multirow[t]{2}{*}{$\lambda$} & \multirow[t]{2}{*}{$\mathrm{P} / \mathrm{P}_{\mathrm{y}}$} \\
\hline & & & & & & & & $\mathrm{t}_{1}$ & $\mathrm{t}_{2}$ & $t_{3}$ & & & \\
\hline BC1 & 3403 & 9.00 & 0.116 & 0.26 & 0.124 & BGC1 & 3403 & 11.25 & 9.00 & 7.75 & 0.116 & 0.26 & 0.124 \\
\hline BC2 & 3403 & 10.45 & 0.100 & 0.26 & 0.124 & BGC2 & 3403 & 13.00 & 10.45 & 9.00 & 0.100 & 0.26 & 0.124 \\
\hline BC3 & 3403 & 13.00 & 0.080 & 0.26 & 0.124 & BGC3 & 3403 & 16.25 & 13.00 & 11.19 & 0.080 & 0.26 & 0.124 \\
\hline BC10 & 3403 & 17.40 & 0.060 & 0.26 & 0.124 & BGC10 & 3403 & 21.78 & 17.42 & 15.00 & 0.060 & 0.26 & 0.124 \\
\hline BC11 & 3403 & 26.13 & 0.040 & 0.26 & 0.124 & BGC11 & 3403 & 32.66 & 26.13 & 22.51 & 0.040 & 0.26 & 0.124 \\
\hline BC4 & 3960 & 9.00 & 0.116 & 0.30 & 0.124 & BGC4 & 3960 & 11.25 & 9.00 & 8.07 & 0.116 & 0.30 & 0.124 \\
\hline BC5 & 3960 & 10.45 & 0.100 & 0.30 & 0.124 & BGC5 & 3960 & 13.00 & 10.45 & 9.37 & 0.100 & 0.30 & 0.124 \\
\hline BC6 & 3960 & 13.00 & 0.080 & 0.30 & 0.124 & BGC6 & 3960 & 16.25 & 13.00 & 11.65 & 0.080 & 0.30 & 0.124 \\
\hline BC6-10 & 3960 & 13.00 & 0.080 & 0.30 & 0.100 & BGC6-10 & 3960 & 16.25 & 13.00 & 11.65 & 0.080 & 0.30 & 0.100 \\
\hline BC6-15 & 3960 & 13.00 & 0.080 & 0.30 & 0.150 & BGC6-15 & 3960 & 16.25 & 13.00 & 11.65 & 0.080 & 0.30 & 0.150 \\
\hline BC6-20 & 3960 & 13.00 & 0.080 & 0.30 & 0.200 & BGC6-20 & 3960 & 16.25 & 13.00 & 11.65 & 0.080 & 0.30 & 0.200 \\
\hline BC6-30 & 3960 & 13.00 & 0.080 & 0.30 & 0.300 & BGC6-30 & 3960 & 16.25 & 13.00 & 11.65 & 0.080 & 0.30 & 0.300 \\
\hline BC12 & 3960 & 17.42 & 0.060 & 0.30 & 0.124 & BGC12 & 3960 & 21.78 & 17.42 & 15.62 & 0.060 & 0.30 & 0.124 \\
\hline BC13 & 3960 & 26.13 & 0.040 & 0.30 & 0.124 & BGC13 & 3960 & 32.66 & 26.13 & 23.44 & 0.040 & 0.30 & 0.124 \\
\hline BC7 & 6600 & 9.00 & 0.116 & 0.50 & 0.124 & BGC7 & 6600 & 11.25 & 9.00 & 8.58 & 0.116 & 0.50 & 0.124 \\
\hline BC8 & 6600 & 10.45 & 0.100 & 0.50 & 0.124 & BGC8 & 6600 & 13.00 & 10.45 & 9.96 & 0.100 & 0.50 & 0.124 \\
\hline BC9 & 6600 & 13.00 & 0.080 & 0.50 & 0.124 & BGC9 & 6600 & 16.25 & 13.00 & 12.39 & 0.080 & 0.50 & 0.124 \\
\hline BC14 & 6600 & 17.42 & 0.060 & 0.50 & 0.124 & BGC14 & 6600 & 21.78 & 17.42 & 16.61 & 0.060 & 0.50 & 0.124 \\
\hline BC15 & 6600 & 26.13 & 0.040 & 0.50 & 0.124 & BGC15 & 6600 & 32.66 & 26.13 & 24.92 & 0.040 & 0.50 & 0.124 \\
\hline
\end{tabular}

For all columns: Diameter $(D)=900 \mathrm{~mm}, \sigma_{y}=289.6 \mathrm{MPa}, E=206 \mathrm{GPa}$, and, $v=0.3$.

All columns are loaded with one-cycle at each displacement $(N=1)$, except BC1 and BGC1 loaded with $N=1$ and 3.

$P_{\mathrm{y}}=\sigma_{\mathrm{y}}{ }^{*} A, A=\pi / 4 *\left(D^{2}-D_{i}^{2}\right), D_{i}=D-2 t, t=$ thickness for the BC column. 
As shown in Fig. 4b, the same FEM details of the tested column, except the FE meshing, are used for both BC and BGC columns. For computational efficiency, the bottom half of the lower part (equal to the cross-section diameter, D) is divided into 26 S4R elements, while the remaining height (D) is only divided into 14 elements. In the circumferential direction of the lower part of the column, 40 S4R elements are used. The upper part of the column (height of h2D) is divided into B31 elements with size of $90 \mathrm{~mm}$.

\section{Hysteresis behavior of BC and BGC columns}

To investigate the hysteretic behavior of BC and BGC columns under constant axial force and bidirectional cyclic lateral loading, a numerical study was conducted using the validated FEM.

Under bidirectional circular cyclic lateral loading, the applied displacement amplitude is equal in both lateral $\mathrm{X}$ and $\mathrm{Z}$ directions. Consequently, the BC and BGC columns exhibit isotropic response in both $\mathrm{X}$ and $\mathrm{Z}$ directions (e.g., see the results in Fig. 2a and b). In this paper, for brevity purpose, the results in the $\mathrm{Z}$ direction are presented in the further analysis.

The normalized lateral load vs. lateral displacement hysteresis loops of both BC and BGC columns are shown in Fig. 5. The results in this figure reveal significant improvements in both strength and ductility when the proposed BGC columns are used. Moreover, the post-buckling of the BGC columns is improved compared to their BC column counterparts. For example, the normalized ultimate strength of BGC1 column (i.e., $\mathrm{H}_{z \max } / \mathrm{H}_{y}=1.45$ ) is $15 \%$ greater than the $\mathrm{BC} 1$ column $\left(\mathrm{H}_{z \max } / \mathrm{H}_{y}=1.26\right)$ as shown in Fig. 5a. For both BC1 and BGC1 columns, the buckling initiates as the normalized maximum displacement corresponding to the ultimate strength approaching 2 (i.e. $\delta_{z m} / \delta_{y}=2$ ). However, the buckling initiates approximately at the same time 
for both BC1 and BGC1 columns, the strength deterioration happens at a rapid rate in the case of the BC1 column compared to BGC1 column. In other words, the $\mathrm{H}_{z m a x} / \mathrm{H}_{y}$ of BC1 column drops by $52 \%$ at $\delta_{z m} / \delta_{y}=4$, while the $\mathrm{H}_{z \max } / \mathrm{H}_{y}$ decreases by $38 \%$ in the BGC1 column. These results indicate the superior behavior of the proposed BGC columns over the BC columns. A similar behavior exists in the all analyzed BC and BGC columns, as shown in Fig. 5)b-f). The comparison of buckling shapes for both BC1 and BGC1 columns is shown in Fig. 6. At the end of FE analysis, the BC1 column bulged outward near the base of the column as expected and formed an elephant-foot-budge buckling mode (see Fig. 6a), while the buckling in the BGC1 column is moved upward from the column base with less severity (see Fig. 6b). A similar buckling was noticed for the all analyzed BC and BGC columns. The main reason for the improved overall behavior of the BGC columns is their ability to mitigate and/or eliminate the local buckling that commonly occurs near the base of the column.
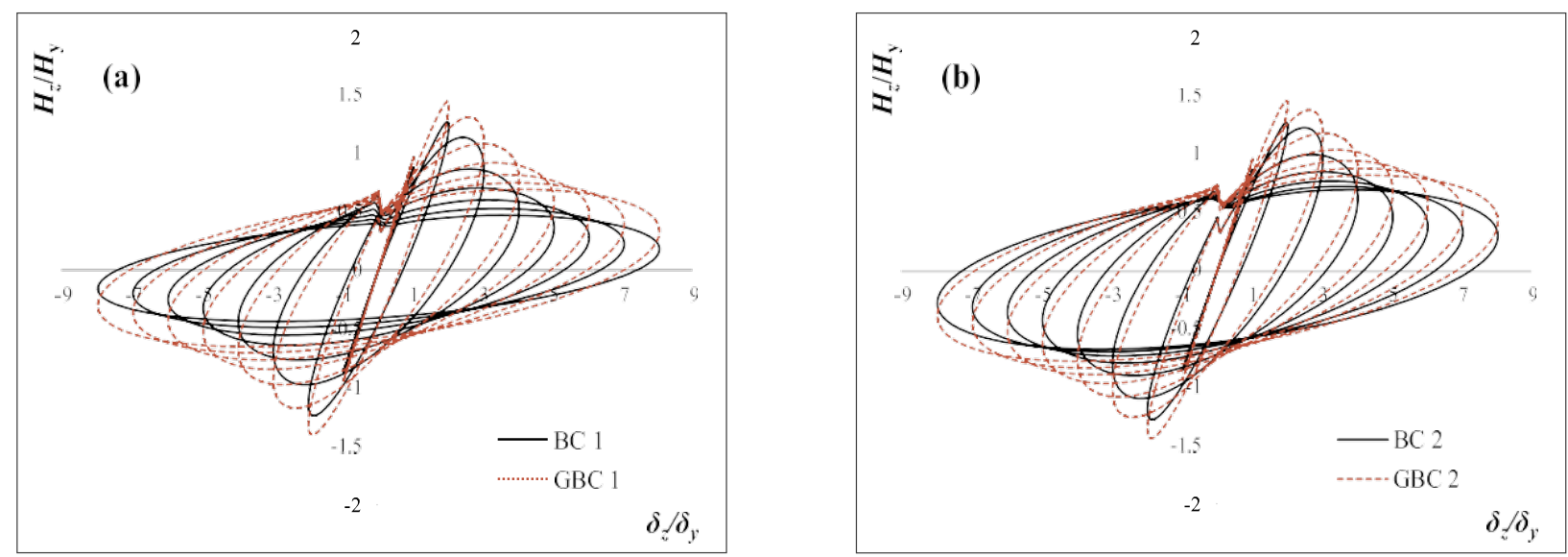

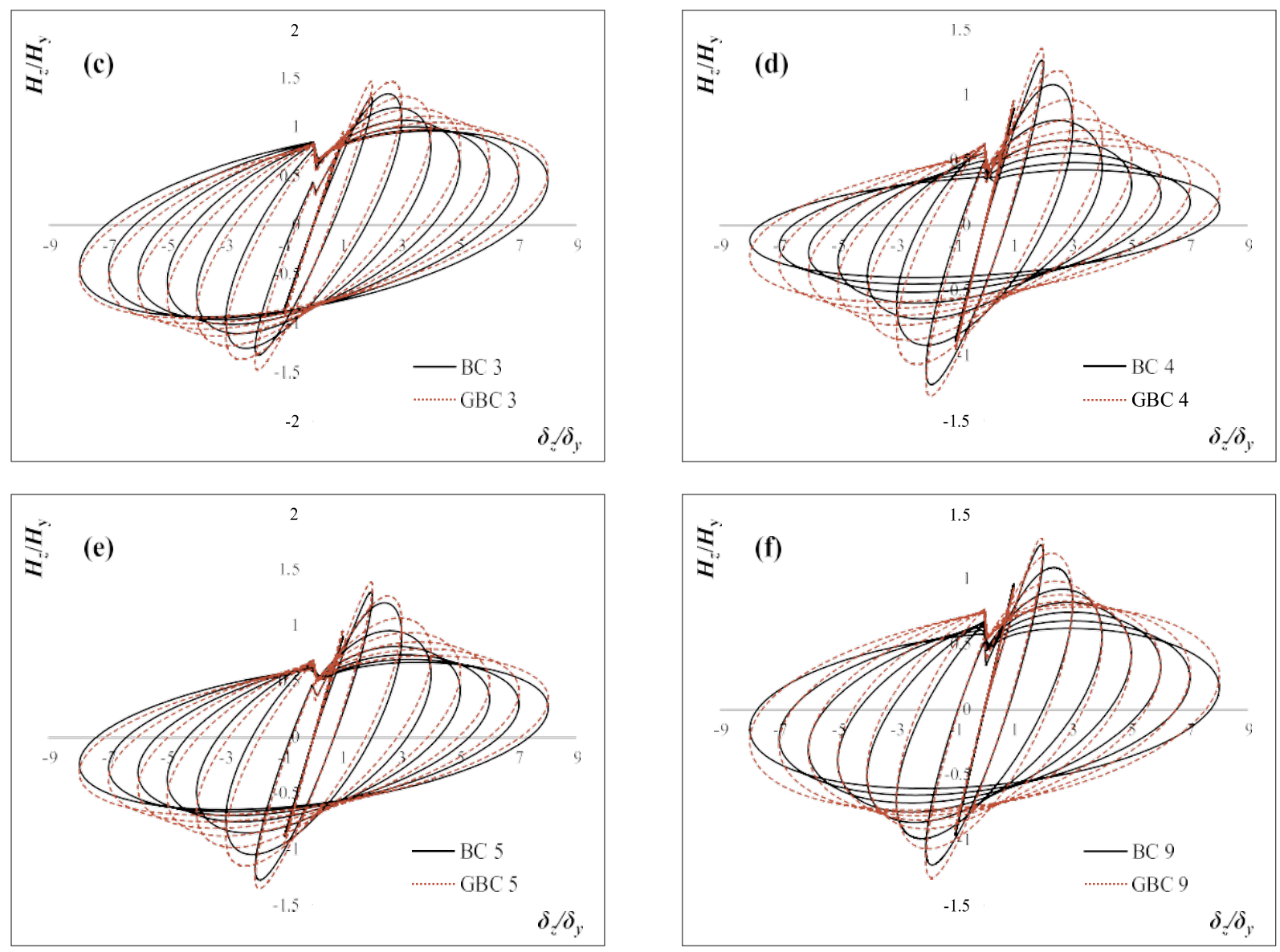

Fig. 5. Comparison of Hysteretic Loops in Z direction of: (a) BC1 \& BGC1, (b) BC2 \& BGC2, (c) BC3 \& BGC3, (d) BC4 \& BGC4, (e) BC5 \& BGC5, and (f) BC9 \& BGC9.

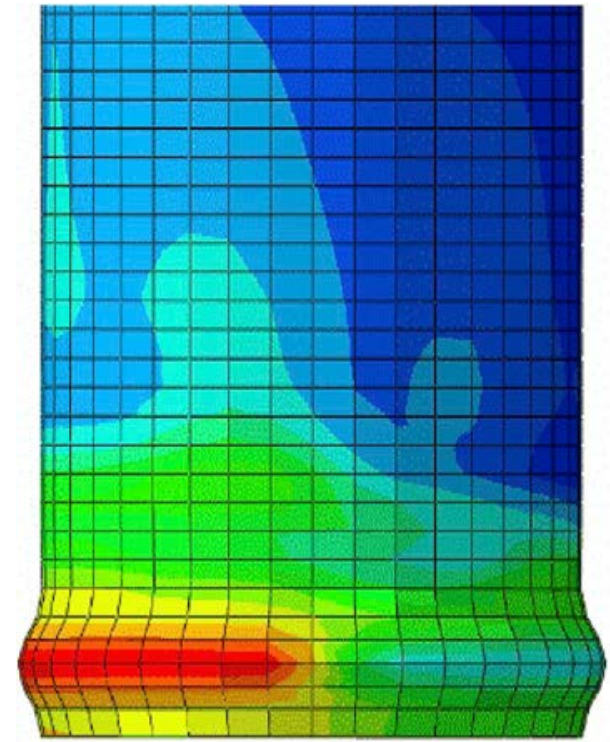

(a) BC1 Column

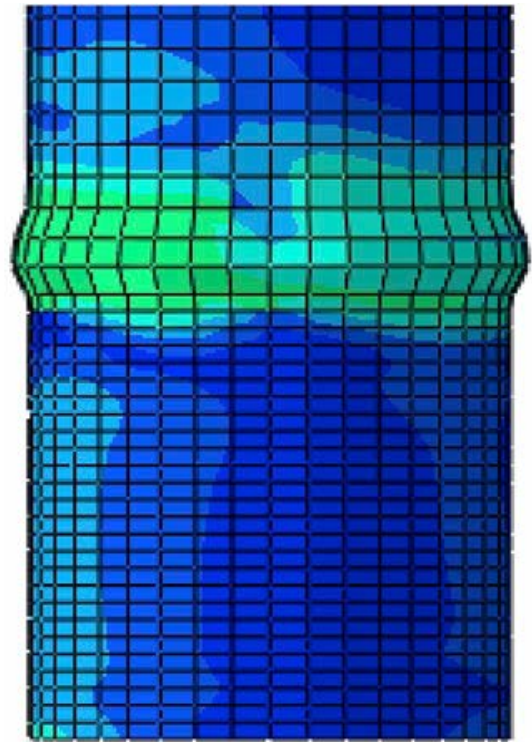

(b) BGC1 Column

Fig. 6. Buckling of BC1 and BGC1 columns. 


\section{Parametric study}

A comprehensive parametric study was conducted to provide insight into the effect of key design parameters including: radius-to-thickness ratio parameter $\left(R_{t}\right)$, column slenderness ratio parameter $(\lambda)$, magnitude of axial load $\left(P / P_{y}\right)$, and number of loading cycles $(N)$, on the overall behavior of the $\mathrm{BC}$ and $\mathrm{BGC}$ columns. The practical range of these parameters in the design of circular bridge piers are: $0.03 \leq R_{t} \leq 0.08,0.2 \leq \lambda \leq 0.4$ and $P / P_{y} \leq 0.2[16,44]$. In this

study, a total of 38 columns, listed in Table 1, is analyzed using the validated FEM in ABAQUS/Standard [33]. The main parameters are: $R_{t}$ varying from 0.04 to $0.116, \lambda$ with a range of 0.26-0.5, the axial load ratio $\left(P / P_{y}\right)$, where five different ratios (i.e., $P / P_{y}=0.1,0.124,0.15$, 0.20, and, 0.3) are applied on BC6 and BGC6 columns, and the number of loading cycles at each displacement amplitude $(N)$. To investigate the effect of $\mathrm{N}$, the BC1 and BGC1 columns were analyzed under both one $(N=1)$, and three $(N=3)$ displacement cycles.

\subsection{Effect of radius-to-thickness ratio parameter $\left(R_{t}\right)$}

The effect of the $R_{t}$ on the strength and ductility of the column was investigated. The increase in $R_{t}$ is either due to an increase in the column radius or a decrease in the thickness. In this study, the columns' diameter is kept constant and the thickness is changed for all the analyzed columns. The normalized lateral load vs. lateral displacement envelope curves for both BC and BGC columns with different values of $R_{t}$ are presented in Fig. 7. The normalized ultimate strength (i.e., $\mathrm{H}_{z \max } / \mathrm{H}_{y}$ ) and normalized maximum displacement corresponding to the ultimate strength (i.e., $\delta_{z m} / \delta_{y}$ ) of both BC and BGC columns are improved by decreasing $R_{t}$ and keeping the other column parameter unchanged. For an example, the $\mathrm{H}_{z m a x} / \mathrm{H}_{y}$ and $\delta_{z m} / \delta_{y}$ are increased by $17 \%$ and $54 \%$, respectively, as $R_{t}$ is decreased from 0.116 (column BC1) to 0.04 (column BC11) with $\lambda=0.26$ (see Fig. 7a). In a similar way, as the $R_{t}$ decreases from 0.116 
(column BGC1) to 0.04 (column BGC11), $\mathrm{H}_{z \max } / \mathrm{H}_{y}$ and $\delta_{z m} / \delta_{y}$ increase by $14 \%$ and 68\%, respectively, as shown in Fig. 7c. After the peak point, the post-buckling curve is less steep as $R_{t}$ gets smaller and the column experiences higher ductile behavior.
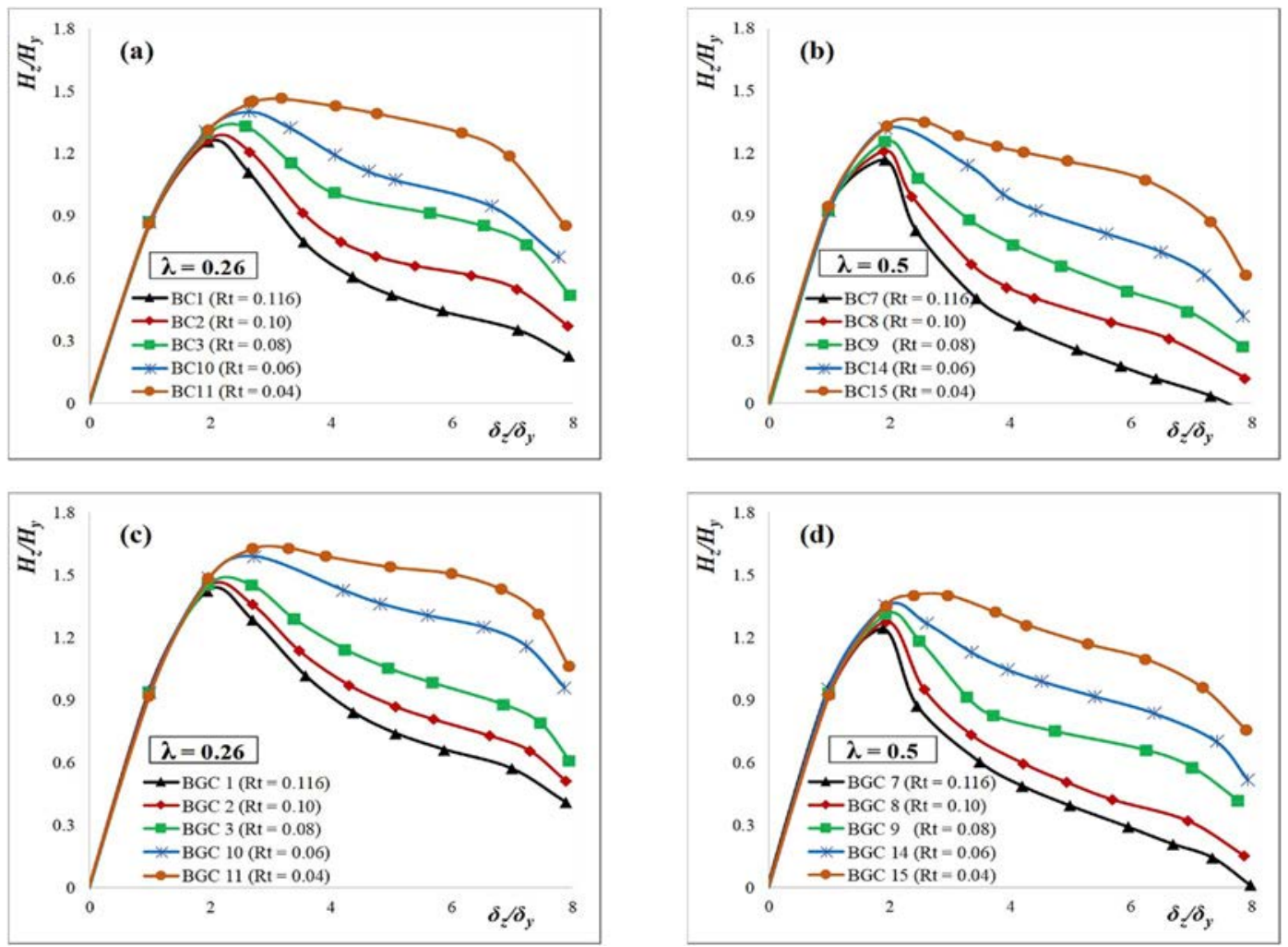

Fig. 7. Effect of $R t$ on Strength and Ductility of: (a) BC columns with $\lambda=0.26$, (b) $B C$ columns with $\lambda=0.5$, (c) BGC columns with $\lambda=0.26$, and (d) BGC columns with $\lambda=0.5$.

\subsection{Effect of slenderness ratio parameter $(\lambda)$}

The effect of the $\lambda$ on the ultimate strength and ductility of both BC and BGC columns was studied. For both BC and BGC columns, the $H_{z m a x} / H_{y}$ and $\delta_{z m} / \delta_{y}$ improve as $\lambda$ gets smaller as illustrated in Fig. 8. For instance, the $H_{z m a x} / H_{y}$ and $\delta_{z m} / \delta_{y}$ are increased by $6 \%$ and 32\%, respectively, as $\lambda$ decreases from 0.5 (column BC9, $R_{t}=0.08$ ) to 0.26 (column BC3, $R_{t}=0.08$ ) as shown in Fig. 8. Similarly, the $H_{z m a x} / H_{y}$ and $\delta_{z m} / \delta_{y}$ are improved by $11 \%$ and $37 \%$, respectively, 
as $\lambda$ decreases from 0.5 (column BGC9, $R_{t}=0.08$ ) to 0.26 (column BGC3, $R_{t}=0.08$ )

when $R_{t}=0.08$ as shown in Fig. $8 \mathrm{~d}$.
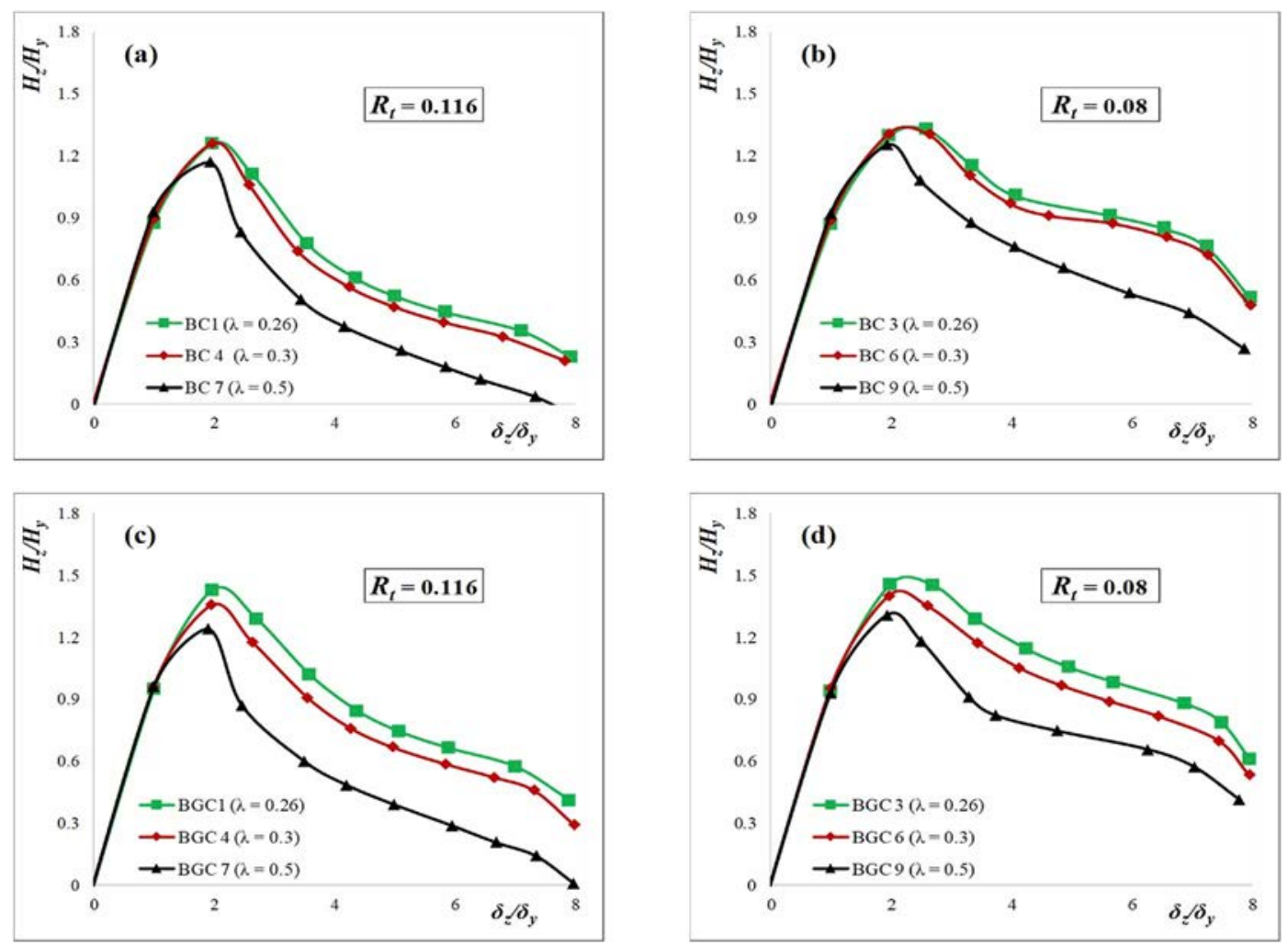

Fig. 8. Effect of $\lambda$ on Strength and Ductility of: (a) BC columns with $R_{t}=0.116$, (b) BC columns with $R_{t}=0.08$ (c) BGC columns with $R_{t}=0.116$, and (d) BGC columns with $R_{t}=0.08$.

After the peak point, the strength decreases in a faster rate for both BC7 (at an average of 73\%) and BGC7 (at an average of $36 \%$ ) columns when $\lambda=0.5$ and $R_{t}=0.116$, while the strength drops less for both BC1 (at an average of 28\%) and BGC1 (at an average of 20\%) in the case of $\lambda=0.26$, and $R_{t}=0.116$. In other words, the post-buckling curve slope gets steeper, and the area enclosed by the envelope curve decreases when $\lambda$ is higher. The same trend exists in all other analyzed columns with different $R_{t}$ values. 


\subsection{Effect of axial load $\left(P / P_{y}\right)$}

The ultimate strength and ductility of the BC and BGC columns were studied under different axial load ratios (i.e., $P / P_{\mathrm{y}}=0.1,0.124,0.15,0.2$, and 0.3 ). Five of $\mathrm{BC} 6$ columns (BC610, BC6-12.4, BC6-15, BC6-20, and BC6-30) and five of the BGC6 columns (BGC6-10, BGC612.4, BGC6-15, BGC6-20, and BGC6-30) are analyzed, where the number after the hyphen indicates the applied axial load ratio. As shown in Fig. 9, the envelope curves of the lateral load $\left(H_{z} / H_{y 0}\right)$ vs. lateral displacement $\left(\delta_{z} / \delta_{y 0}\right)$ are normalized by $H_{y 0}$ (lateral yield load under zero axial load) and $\delta_{y 0}$ (yield displacement under zero axial load) to highlight the axial load effect. For both BC6 and BGC6, the ultimate strength (i.e., $H_{z \max } / H_{y 0}$ ) decreases as the axial load ratio $\left(P / P_{y}\right)$ increases due to the $P-\Delta$ effect in the case of large axial loads. For example, the $H_{z \max } / H_{y 0}$ and $\delta_{z m} / \delta_{y 0}$ are increased by $17 \%$ and $8 \%$, respectively, when $P / P_{\mathrm{y}}$ decreases from 30\% (column BC6-30) to 10\% (column BC6-10). In the case of BGC columns, the $H_{z \max } / H_{y 0}$ and $\delta_{z m} / \delta_{y 0}$ are increased by $30 \%$ and $28 \%$, respectively, when $P / P_{y}$ decreases from 30\% (column BGC6-30) to 10\% (column BGC6-10). Furthermore, the post-buckling curve slope becomes steeper, which, in turn, dissipates less energy, as observed in the cases of BC6-30 and BGC6-30, while more energy is dissipated in the cases of BC6-10 and BGC6-10, respectively.

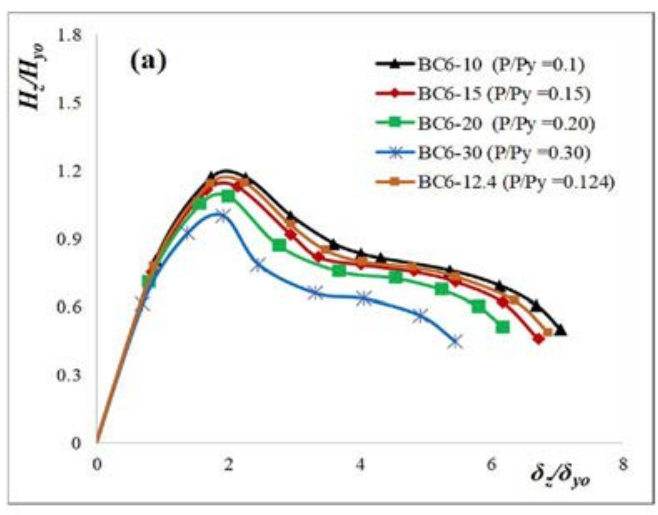

(a) BC6 Column

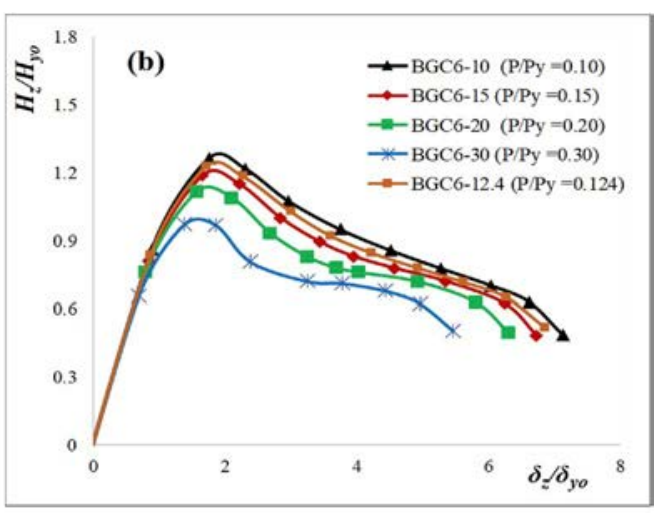

(b) BGC6 Column

Fig. 9. Effect of axial load on strength and ductility. 


\subsection{Effect of number of loading cycles $(N)$}

The normalized lateral load vs. lateral displacement envelope curves of the BC1 (Fig. 10a) and BGC1 (Fig. 10b) columns in the cases of one $(N=1)$ and three $(N=3)$ loading cycles at each displacement level are presented in Fig. 10. After $\delta=2 \delta_{y}$, the column strength drops at a faster rate, and larger damage is noticed in the case of $N=3$ compared to $N=1$. For instance, $\mathrm{BC} 1$ and BGC1 slopes, respectively, decrease at an average of $28 \%$ and $20 \%$ in the case of $N=1$, while the slopes decrease at an average of $34 \%$ and $27 \%$ in the case of $N=3$. No remarkable effect is observed when $\delta$ is less than $2 \delta_{y}$, which might be due to the small plastic deformation. It is worth noting that the deterioration in the BGC1 column is less than in the BC1 column under both $N=1$ and $N=3$.



(b) $\mathrm{BC} 1$ Column

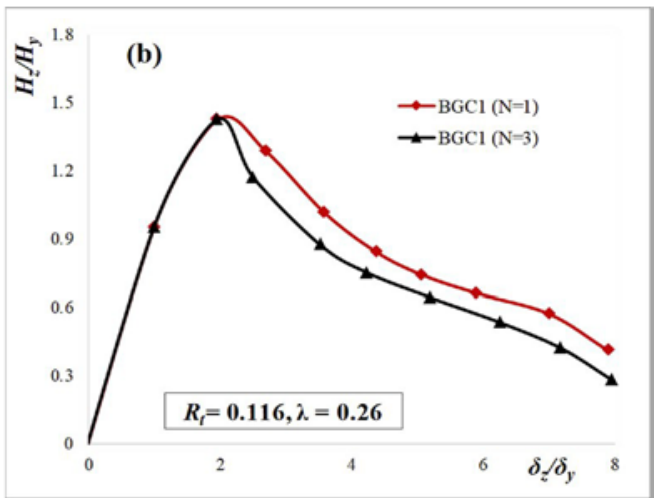

(b) BGCl Column

Fig. 10. Effect of $N$ on ductility capacity.

\section{Strength and ductility evaluation of BC and BGC columns}

Table 2 lists the computed ultimate strength and ductility values of both BC and BGC columns. In Fig. $11, H_{z \max } / H_{y}$ is plotted against integrated parameters $\left(1+P / P_{y}\right) R_{t} \lambda$ considering the interaction of $R_{t}, \lambda$, and $P / P_{y}$ on the strength of the column. Equations (5), (6)) are proposed to fit the computed ultimate strength of BC and BGC columns, respectively: 


$$
\begin{aligned}
\frac{H_{z \max }}{H_{y}} & =\frac{0.841}{\left[\left(1+\frac{P}{P_{y}}\right) R_{t} \lambda\right]^{0.126}} \\
\frac{H_{z \max }}{H_{y}} & =\frac{0.734}{\left[\left(1+\frac{P}{P_{y}}\right) R_{t} \lambda\right]^{0.18}}
\end{aligned}
$$

BC Columns

BGC Columns

(6)

\begin{tabular}{|c|c|c|c|c|c|c|c|c|c|c|c|}
\hline \multicolumn{6}{|c|}{ BC Columns } & \multicolumn{6}{|c|}{ BGC Columns } \\
\hline Column & $\mathrm{H}_{\mathrm{y}}(\mathrm{KN})$ & $\delta_{\mathrm{y}}(\mathrm{mm})$ & $\mathrm{H}_{\mathrm{zmax}} / \mathrm{H}_{\mathrm{y}}$ & $\delta_{\mathrm{zm}} / \delta_{\mathrm{y}}$ & $\delta_{\mathrm{z} 0.9} / \delta_{\mathrm{y}}$ & Column & $\mathrm{H}_{\mathrm{y}}(\mathrm{KN})$ & $\delta_{\mathrm{y}}(\mathrm{mm})$ & $\mathrm{H}_{\text {zmax }} / \mathrm{H}_{\mathrm{y}}$ & $\delta_{\mathrm{zm}} / \delta_{\mathrm{y}}$ & $\delta_{\mathrm{z} 0.9} / \delta_{\mathrm{y}}$ \\
\hline BC1 & 414.2 & 10.6 & 1.26 & 1.95 & 2.53 & BGC1 & 414.2 & 10.6 & 1.45 & 1.96 & 2.63 \\
\hline BC2 & 478.7 & 10.6 & 1.26 & 1.97 & 2.87 & BGC2 & 478.7 & 10.6 & 1.46 & 1.97 & 2.87 \\
\hline BC3 & 593.2 & 10.6 & 1.33 & 2.54 & 3.16 & BGC3 & 593.2 & 10.6 & 1.46 & 2.65 & 3.30 \\
\hline BC10 & 779.5 & 10.6 & 1.40 & 2.60 & 3.68 & BGC10 & 779.5 & 10.6 & 1.61 & 2.74 & 4.02 \\
\hline BC11 & 1135.5 & 10.6 & 1.47 & 3.01 & 5.80 & BGC11 & 1135.5 & 10.6 & 1.65 & 3.30 & 6.26 \\
\hline BC4 & 355.9 & 14.3 & 1.27 & 1.95 & 2.33 & BGC4 & 355.9 & 14.3 & 1.38 & 1.95 & 2.39 \\
\hline BC5 & 411.4 & 14.3 & 1.29 & 1.96 & 2.59 & BGC5 & 411.4 & 14.3 & 1.40 & 1.96 & 2.66 \\
\hline BC6 & 509.8 & 14.3 & 1.31 & 1.97 & 3.02 & BGC6 & 509.8 & 14.3 & 1.40 & 1.97 & 3.07 \\
\hline BC6-10 & 523.7 & 14.3 & 1.30 & 1.95 & 3.05 & BGC6-10 & 523.7 & 14.3 & 1.40 & 1.95 & 3.04 \\
\hline BC6-15 & 494.6 & 14.3 & 1.33 & 1.96 & 3.00 & BGC6-15 & 494.6 & 14.3 & 1.40 & 1.96 & 3.00 \\
\hline BC6-20 & 465.5 & 14.3 & 1.36 & 1.96 & 2.97 & BGC6-20 & 465.5 & 14.3 & 1.39 & 1.96 & 3.03 \\
\hline BC6-30 & 407.3 & 14.3 & 1.38 & 1.96 & 3.10 & BGC6-30 & 407.3 & 14.3 & 1.39 & 1.96 & 3.13 \\
\hline BC12 & 669.8 & 14.3 & 1.39 & 2.53 & 3.54 & BGC12 & 669.8 & 14.3 & 1.50 & 2.66 & 3.89 \\
\hline $\mathrm{BC} 13$ & 975.8 & 14.3 & 1.45 & 2.73 & 5.77 & BGC13 & 975.8 & 14.3 & 1.56 & 2.74 & 6.00 \\
\hline BC7 & 213.6 & 39.7 & 1.17 & 1.90 & 2.02 & BGC7 & 213.6 & 39.7 & 1.24 & 1.90 & 2.15 \\
\hline BC8 & 246.8 & 39.7 & 1.21 & 1.91 & 2.07 & BGC8 & 246.8 & 39.7 & 1.28 & 1.92 & 2.23 \\
\hline BC9 & 305.9 & 39.7 & 1.25 & 1.93 & 2.17 & BGC9 & 305.9 & 39.7 & 1.31 & 1.93 & 2.65 \\
\hline BC14 & 401.9 & 39.7 & 1.32 & 1.93 & 2.89 & BGC14 & 401.9 & 39.7 & 1.35 & 2.31 & 2.95 \\
\hline BC15 & 585.5 & 39.7 & 1.35 & 2.45 & 3.38 & BGC15 & 585.5 & 39.7 & 1.40 & 2.78 & 4.73 \\
\hline
\end{tabular}

Table 2 Strength and ductility of analyzed BC and BGC columns

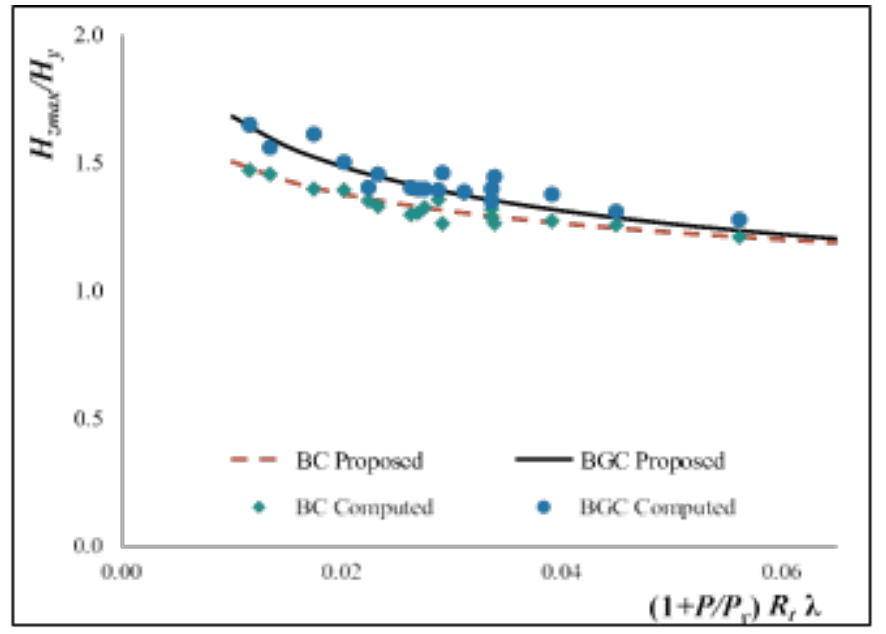

Fig. 11. Ultimate strength of the BC and BGC columns. 
The ultimate strength of both BC and BGC columns is improved when integrated parameters $\left(1+P / P_{y}\right) R_{t} \lambda$ decrease as illustrated in Fig. 11. The failure of thin-walled steel columns is considered to have occurred when the displacement equals either $\delta_{z m}$ or $\delta_{z 0.9}$. The $\delta_{z m}$ is the displacement corresponding to $H_{z \max } / H_{y}$, where the $\delta_{z 0.9}$ is defined as the displacement where the post-peak strength drops to $90 \%$ of $H_{z \max } / H_{y}$ after the peak $[15,16,45]$. The $\delta_{z m} / \delta_{y}$ and $\delta_{z 0.9} / \delta_{y}$ are key parameters used to evaluate the ductility performance for both BC and BGC columns. Moreover, the strength of thin-walled steel columns decreases significantly after the peak due to the influence of local buckling. Therefore, it is more reasonable to use the $\delta_{z 0.9} / \delta_{y}$ parameter to evaluate ductility $[16,17,46]$. Table 2 shows an increasing trend of the strength and ductility in both the BC and BGC columns as the $R_{t}$ and $\lambda$ decrease. All $\delta_{z m} / \delta_{y}$ and $\delta_{z 0.9} / \delta_{y}$ values of both BC and BGC columns are plotted versus integrated $R_{t}, \lambda$ and/or $P / P_{\mathrm{y}}$, as shown in Fig. 12.
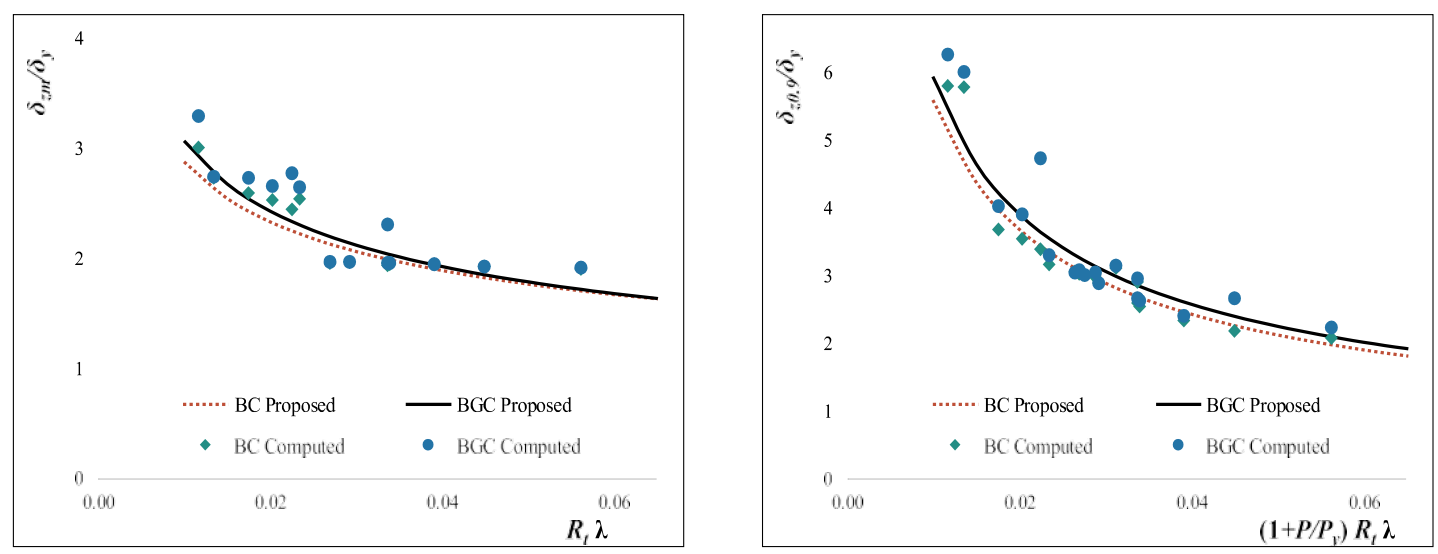

Fig. 12. Ductility of BC and BGC Columns: (a) $\delta_{z m} / \delta_{y}$, (b) $\delta_{z 0.9} / \delta_{y}$.

The proposed formulae that fit the computed $\delta_{z m} / \delta_{y}$ and $\delta_{z 0.9} / \delta_{y}$ values of the analyzed columns are as follows:

$$
\frac{\delta_{z m}}{\delta_{y}}=\frac{0.713}{\left(R_{t} \lambda\right)^{0.303}}
$$




$$
\begin{aligned}
& \frac{\delta_{z 0.9}}{\delta_{y}}=\frac{0.352}{\left[\left(1+\frac{P}{P_{y}}\right) R_{t} \lambda\right]^{0.6}} \\
& \frac{\delta_{z m}}{\delta_{y}}=\frac{0.649}{\left(R_{t} \lambda\right)^{0.337}} \\
& \frac{\delta_{z 0.9}}{\delta_{y}}=\frac{0.373}{\left[\left(1+\frac{P}{P_{y}}\right) R_{t} \lambda\right]^{0.6}}
\end{aligned}
$$

As can be seen from Fig. 9, the axial load magnitude has a significant effect on the post-buckling of the BC and BGC columns. Therefore, the axial load influence is considered in the fitting of the ductility parameter $\delta_{z 0.9} / \delta_{y}$ as it appears in Equations (8), (10)). In contrast, the axial load has an insignificant effect on the maximum displacement of the BC and BGC columns. Thus, the axial load influence is not included in the fitting of the $\delta_{z m} / \delta_{y}$ parameter, as shown in Equations (7), (9)). The applicable restrictions of these formulae are $0.04 \leq R_{t} \leq 0.116,0.26 \leq$ $\lambda \leq 0.5$, and $P / P_{y} \leq 0.3$. It is worth mentioning that nonlinear least-squares regression was used for the curve fitting.

\section{Conclusion}

This paper aims to evaluate the strength and ductility of thin-walled steel tubular circular columns with uniform thickness (BC) and graded thickness (BGC) under constant axial force and bidirectional cyclic lateral loading. The effect of main design parameters including: radiusto-thickness ratio parameter $\left(R_{t}\right)$, column slenderness ratio parameter $(\lambda)$, magnitude of axial load $\left(P / P_{y}\right)$, and number of loading cycles $(N)$ on the strength and ductility of both BC and BGC 
columns under bidirectional cyclic lateral loading was investigated. From this study, the following conclusions are drawn:

- The numerical results, obtained by using the adopted FEM, show a reasonable agreement with the experimental results confirming FEM ability to capture the column cyclic elastoplastic behavior under constant axial force and bidirectional cyclic lateral loading.

- The proposed BGC with the same size and volume of material of counterpart of uniform BC column, under constant axial force and circular bidirectional cyclic lateral loading, is proved to have a superiority and significant improvement in the strength, ductility, and post-buckling compared to counterpart of the BC column. In general, the ultimate strength of BGC columns was improved by $13 \%$ and $8 \%$ as $\lambda=0.26$ and 0.3 , respectively. In the case of $\lambda=0.5$, the ultimate strength was improved by only $4 \%$ for the BGC columns compared to BC columns.

- The parametric study concluded that the ultimate strength, ductility, and post buckling of BC and BGC columns improve with the decrease of $R_{t}$ and $\lambda$, while deteriorate when the axial load increases. As the number of loading cycles $(N)$ at each displacement level increases, more strength deterioration happens when $\delta>2 \delta_{\mathrm{y}}$.

- Based on the extensive parametric study, design formulae in predicting the ultimate strength and ductility of the BC and BGC columns have been derived

\section{Declaration of competing interest}

None. 


\section{References}

[1] K. Jaiswal, D. Bausch, J. Rozelle, J. Holub, S. McGowan, Hazus® Estimated Annualized Earthquake Losses for the United States (No. FEMA P-366), 2017.

[2] D.K. Miller, Lessons learned from the Northridge earthquake, Eng. Struct. 20 (1998) 249260, https://doi.org/10.1016/S0141-0296(97)00031-X.

[3] M. Nakashima, K. Inoue, M. Tada, Classification of damage to steel buildings observed in the 1995 Hyogoken-Nanbu earthquake, Eng. Struct. 20 (1998) 271-281, https://doi.org/10.1016/S0141-0296(97)00019-9.

[4] L. Guo, S. Yang, H. Jiao, Behavior of thin-walled circular hollow section tubes subjected to bending, Thin-Walled Struct. 73 (2013) 281-289, https://doi.org/ 10.1016/J.TWS.2013.08.014.

[5] O. Bedair, Novel design procedures for rectangular hollow steel sections subject to compression and major and minor Axis bending, Pract. Period. Struct. Des. Constr. 20 (2015), 04014051, https://doi.org/10.1061/(ASCE)SC.1943-5576.0000248.

[6] Z. Tao, L.H. Han, Z. Bin Wang, Experimental behaviour of stiffened concrete-filled thinwalled hollow steel structural (HSS) stub columns, J. Constr. Steel Res. 61 (2005) 962983, https://doi.org/10.1016/j.jcsr.2004.12.003.

[7] A. Ucak, P. Tsopelas, Load path effects in circular steel columns under bidirectional lateral cyclic loading, J. Struct. Eng. 141 (2014) 1-11, https://doi.org/10.1061/ (ASCE)ST.1943541X.0001057.

[8] Goto, K. Mizuno, G. Prosenjit Kumar, Nonlinear finite element analysis for cyclic behavior of thin-walled stiffened rectangular steel columns with in-filled concrete, J. Struct. Eng. 138 (2012) 571-584, https://doi.org/10.1061/(ASCE)ST.1943- 541X.0000504.

[9] J.-Y. Jiang, D. Wang, H.-Y. Chu, H. Ma, Y. Liu, Y. Gao, J. Shi, W. Sun, The Passive Film Growth Mechanism of New Corrosion-Resistant Steel Rebar in Simulated Concrete Pore Solution: Nanometer Structure and Electrochemical Study, (n.d.). doi:10.3390/ma10040412.

[10] O. Zhao, B. Rossi, L. Gardner, B. Young, Behaviour of structural stainless steel crosssections under combined loading - Part I: experimental study, Eng. Struct. 89 (2015) 236-246, https://doi.org/10.1016/j.engstruct.2014.11.014.

[11] T. Aoki, K.A.S. Susantha, Seismic performance of rectangular-shaped steel piers under cyclic loading, J. Struct. Eng. 131 (2005) 240-249, https://doi.org/ 10.1061/(ASCE)07339445(2005)131:2(240).

[12] H. Ge, S. Gao, T. Usami, Stiffened steel box columns. Part 1: cyclic behaviour, Earthq. Eng. Struct. Dyn. 29 (2000) 1691-1706, https://doi.org/10.1002/10969845(200011)29:11<1691::AID-EQE989>3.0.CO;2-U.

[13] I.H.P. Mamaghani, T. Usami, E. Mizuno, Cyclic elastoplastic large displacement behaviour of steel compression members, J. Struct. Eng. 42 (1996) 135-145. 
[14] I.H.P. Mamaghani, T. Usami, E. Mizuno, Hysteretic behavior of compact steel box beamcolumns, J. Struct. Eng. JSCE, Japan. 43A (1997) 187-194.

[15] Q. Al-Kaseasbeh, I.H.P. Mamaghani, Buckling strength and ductility evaluation of thinwalled steel tubular columns with uniform and graded thickness under cyclic loading, J. Bridge Eng. 24 (2018), 04018105, https://doi.org/10.1061/(ASCE) BE.19435592.0001324.

[16] T. Usami, Interim guidelines and new technologies for seismic design of steel structures, in: Comm. New Technol. Steel Struct, JSCE, Tokyo, 1996 (in Japanes).

[17] S. Gao, T. Usami, H. Ge, Ductility evaluation of steel bridge piers with pipe sections, J. Eng. Mech. 124 (1998) 260, https://doi.org/10.1061/(ASCE)0733-9399(1998)124:3(260).

[18] I.H.P. Mamaghani, J.A. Packer, Inelastic behaviour of partially concrete-filled steel hollow sections, in: 4th Struct. Spec. Conf, 2002, pp. 1-10.

[19] J. Dang, H. Yuan, A. Igarashi, T. Aoki, Multiple-spring model for square-section steel bridge columns under bidirectional seismic load, J. Struct. Eng. 143 (2017), 04017005, https://doi.org/10.1061/(ASCE)ST.1943-541X.0001735.

[20] E. Watanabe, K. Sugiura, F. of JSCE, M. of JSCE, A. Professor, Effects of multi-directional displacement paths on the cyclic behaviour of rectangular hollow steel columns, Dob. Gakkai Ronbunshu (2000) 79-95, https://doi.org/10.2208/ jscej.2000.647_79, 2011.

[21] E.L. Anderson, S.A. Mahin, An evaluation of Bi-directional earthquake shaking on the provisions of the AASHTO guide specifications for seismic isolation design, in: Proc. 13th World Conf. Eq. Eng, 2004.

[22] U.T. Okazaki, K. A, Elasto-plastic dynamic analysis of steel bridge piers subjected to bidirectional earthquakes, J. Struct. Eq. Eng. JSCE. 27 (2003) 1-8.

[23] T. Aoki, A. Ohnishi, M. Suzuki, Experimental study on the seismic resistance performance of rectangular cross section steel bridge piers subjected to Bi-directional horizontal loads, Dob. Gakkai Ronbunshu A 63 (2007) 716-726, https://doi.org/10.2208/jsceja.63.716.

[24] J. Dang, T. Aoki, Bidirectional loading hybrid tests of square cross-sections of steel bridge piers, Earthq. Eng. Struct. Dyn. 42 (2013) 1111-1130, https://doi.org/ 10.1002/eqe.2262.

[25] Y. Goto, R. Koyama, Y. Fujll, M. OBATA, Ultimate state of thin-walled stiffened rectangular steel columns under Bi-directional seismic excitations, Dob. Gakkai Ronbunshu A 65 (2009) 61-80, https://doi.org/10.2208/jsceja.65.61.

[26] K. Jiang Goto, M. Obata, Stability and ductility of thin-walled circular steel columns under cyclic bidirectional loading, J. Struct. Eng. 132 (2006) 1621-1631, https://doi.org/10.1061/(asce)0733-9445(2006)132:10(1621).

[27] A. Onishi, T. Aoki, M. Suzuki, Experimental study on the seismic resistance performance of steel bridge subjected to bi-directional horizontal loads, Bull. Aichi Inst. Tech. 40 (2005) 121-129. 
[28] W. Oyawa, E. Watanabe, K. Sugiura, Finite element studies on hollow steel columns under multi-directional cyclic loads, J. Civ. Eng. Res. Pract. 1 (2004) 33-49.

https://www.ajol.info/index.php/jcerp/article/view/29118. (Accessed 6 October 2018).

[29] E. Watanabe, K. Sugiura, F. of JSCE, M. of JSCE, A. Professor, Effects of MultiDirectional Displacement Paths on the Cyclic Behaviour of Rectangular Hollow Steel Columns, 2000.

[30] L. Jiang, Y. Goto, M. Obata, Hysteretic modeling of thin-walled circular steel columns under biaxial bending, ASCE J. Struct. Eng. 128 (2002) 319-327, https:// doi.org/10.1061/(ASCE)0733-9445(2002)128:3(319).

[31] K. Nishikawa, S. Yamamoto, T. Natori, K. Terao, H. Yasunami, M. Terada, Retrofitting for seismic upgrading of steel bridge columns, Eng. Struct. 20 (1998) 540-551, https://doi.org/10.1016/S0141-0296(97)00025-4.

[32] T. Wang, X. Xie, C. Shen, Z. Tang, Effect of hysteretic constitutive models on elasto-plastic seismic performance evaluation of steel arch bridges, Earthquakes Struct 10 (2016) 1089-1109, https://doi.org/10.12989/eas.2016.10.5.1089.

[33] Karlsson Hibbit, Sorensen, ABAQUS 2014 Documentation, 2014.

[34] J.L. Chaboche, Time-independent constitutive theories for cyclic plasticity, Int. J. Plast. 2 (1986) 149-188, https://doi.org/10.1016/0749-6419(86)90010-0.

[35] M.S. Hassan, S. Salawdeh, J. Goggins, Determination of geometrical imperfection models in finite element analysis of structural steel hollow sections under cyclic axial loading, J. Constr. Steel Res. 141 (2018) 189-203, https://doi.org/10.1016/ J.JCSR.2017.11.012.

[36] I.H.P. Mamaghani, C. Shen, E. Mizuno, T. Usami, Cyclic behavior of structural steels. I: experiments,, J. Eng. Mech. 121 (1995) 1158-1164, https://doi.org/ 10.1061/(ASCE)0733-9399(1995)121:11(1158).

[37] C. Shen, I.H.P. Mamaghani, E. Mizuno, T. Usami, Cyclic behavior of structural steels. II: theory, J. Eng. Mech. 121 (1995) 1165-1172, https://doi.org/10.1061/ (ASCE)07339399(1995)121:11(1165).

[38] S. Chen, X. Xie, H. Zhuge, Hysteretic model for steel piers considering the local buckling of steel plates, Eng. Struct. 183 (2019) 303-318, https://doi.org/ 10.1016/j.engstruct.2018.12.101.

[39] S. Banno, I.H.P. Mamaghani, T. Usami, E. Mizuno, Cyclic elastoplastic large deflection analysis of thin steel plates, J. Eng. Mech. 124 (1998) 363-370, https:// doi.org/10.1061/(ASCE)0733-9399(1998)124:4(363).

[40] A. Ucak, P. Tsopelas, Accurate modeling of the cyclic response of structural components constructed of steel with yield plateau, Eng. Struct. 35 (2012) 272-280, https://doi.org/10.1016/j.engstruct.2011.10.015.

[41] Q. Al-Kaseasbeh, I.H.P. Mamaghani, Buckling strength and ductility evaluation of thinwalled steel stiffened square box columns with uniform and graded thickness under 
cyclic loading, Eng. Struct. 186 (2019) 498-507, https://doi.org/10.1016/j.

engstruct.2019.02.026.

[42] I.H.P. Mamaghani, T. Usami, E. Mizuno, Inelastic large deflection analysis of structural steel members under cyclic loading, Eng. Struct. 18 (1996) 659-668, https://doi.org/10.1016/0141-0296(96)00204-0.

[43] ASTM, ASTM A36/A36M - 14 Standard Specification for Carbon Structural Steel, ASTM Int. West, Conshohocken, PA, 2014, pp. 12-14, https://doi.org/10.1520/ A0036.

[44] D.M. Frangopol, D. Saydam, Structural performance indicators for bridges, in: Bridg. Eng. Handb. Fundam, 2ndd., CRC Press, 2014, pp. 185-206, https://doi. org/10.1201/b15616.

[45] I.H.P. Mamaghani, F. Ahmad, B. Dorose, Strength and ductility evaluation of steel tubular columns under cyclic multiaxial loading, in: ISTS15 - 15th Int. Symp. Tubul. Struct, 2015. Rio, Brasil.

[46] T. Usami, S. Gao, H. Ge, Stiffened steel box columns. Part 2: ductility evaluation, Earthq. Eng. Struct. Dyn. 29 (2000) 1707-1722, https://doi.org/10.1002/10969845(200011)29:11<1707::AID-EQE990>3.0.CO;2-7. 